\title{
The glycocalyx: a novel diagnostic and therapeutic target in sepsis
}

\author{
Ryo Uchimido ${ }^{{ }^{*}}$ (D), Eric P. Schmidt ${ }^{2}$ and Nathan I. Shapiro ${ }^{1}$
}

\begin{abstract}
The glycocalyx is a gel-like layer covering the luminal surface of vascular endothelial cells. It is comprised of membrane-attached proteoglycans, glycosaminoglycan chains, glycoproteins, and adherent plasma proteins. The glycocalyx maintains homeostasis of the vasculature, including controlling vascular permeability and microvascular tone, preventing microvascular thrombosis, and regulating leukocyte adhesion.

During sepsis, the glycocalyx is degraded via inflammatory mechanisms such as metalloproteinases, heparanase, and hyaluronidase. These sheddases are activated by reactive oxygen species and pro-inflammatory cytokines such as tumor necrosis factor alpha and interleukin-1 beta. Inflammation-mediated glycocalyx degradation leads to vascular hyper-permeability, unregulated vasodilation, microvessel thrombosis, and augmented leukocyte adhesion. Clinical studies have demonstrated the correlation between blood levels of glycocalyx components with organ dysfunction, severity, and mortality in sepsis.

Fluid resuscitation therapy is an essential part of sepsis treatment, but overaggressive fluid therapy practices (leading to hypervolemia) may augment glycocalyx degradation. Conversely, fresh frozen plasma and albumin administration may attenuate glycocalyx degradation. The beneficial and harmful effects of fluid and plasma infusion on glycocalyx integrity in sepsis are not well understood; future studies are warranted.

In this review, we first analyze the underlying mechanisms of glycocalyx degradation in sepsis. Second, we demonstrate how the blood and urine levels of glycocalyx components are associated with patient outcomes. Third, we show beneficial and harmful effects of fluid therapy on the glycocalyx status during sepsis. Finally, we address the concept of glycocalyx degradation as a therapeutic target.
\end{abstract}

Keywords: Glycocalyx, Vascular endothelial cell, Glycocalyx degradation, Heparan sulfate, Syndecan, Hyaluronan, Fluid therapy, Fibroblast growth factor, Sepsis

\section{Introduction}

The glycocalyx is a gel-like layer lining the luminal surface of endothelial cells, composed of membrane-bound proteoglycans, glycoproteins, glycosaminoglycans, and adherent plasma proteins [1]. It performs several functions necessary for vascular homeostasis: it regulates vascular permeability and microvascular tone, inhibits microvascular thrombosis, and helps regulate leukocyte adhesion on the endothelium [2-4]. During sepsis, glycocalyx degradation occurs due to a combination of pathophysiologic insults, potentially compounded by iatrogenic effects of accompanying fluid resuscitation

\footnotetext{
* Correspondence: ruchimido@hsph.harvard.edu

'Department of Emergency Medicine, Beth Israel Deaconess Medical Center,

1 Deaconess Road, Boston, MA 02215, USA

Full list of author information is available at the end of the article
}

practices [5-9]. Glycocalyx fragments shed into the blood during sepsis may serve as clinically relevant biomarkers, given the pathophysiologic implications of glycocalyx degradation. The degradation of glycocalyx is also thought to contribute to microcirculatory dysfunction in sepsis [10]. The objectives of this article are to review: 1) human studies that investigate the association of biomarkers of glycocalyx degradation with clinical outcomes, 2) mechanisms of glycocalyx degradation, and 3) the potential of the glycocalyx as a therapeutic target in sepsis.

\section{Background \\ Components and structure}

The glycocalyx is a layer that lines the luminal surface of vascular endothelial cells (Fig. 1). The thickness and structure of the glycocalyx vary across different species,

(c) The Author(s). 2019 Open Access This article is distributed under the terms of the Creative Commons Attribution 4.0 International License (http://creativecommons.org/licenses/by/4.0/), which permits unrestricted use, distribution, and 


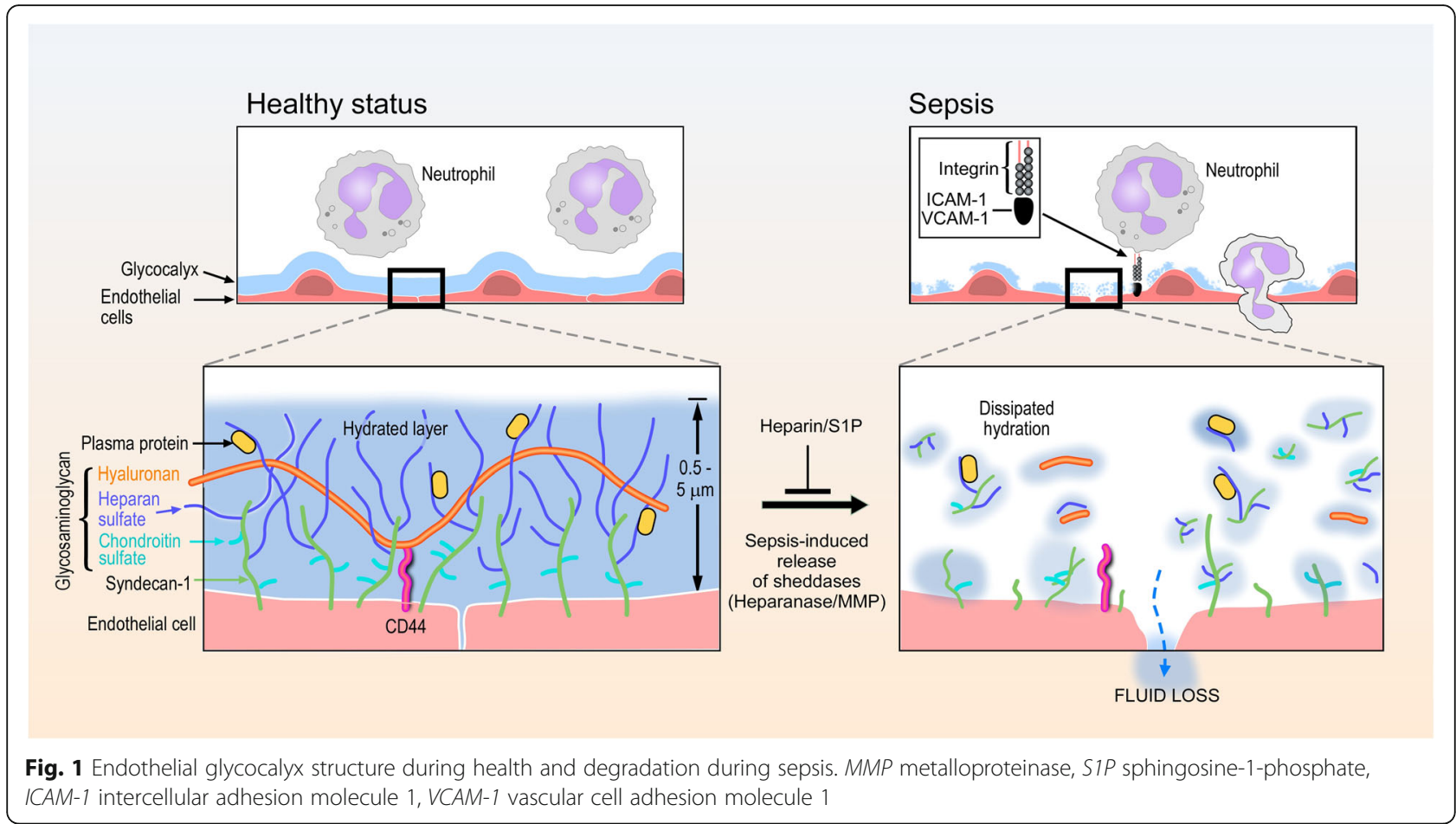

vascular beds, organs, and blood flow rates [11]. Its observed thickness in humans is approximately 0.5 to $5.0 \mu \mathrm{m} \mathrm{[12-18].} \mathrm{The} \mathrm{glycocalyx} \mathrm{consists} \mathrm{of} \mathrm{proteo-}$ glycans (PG), glycoproteins bound with sialic acid, glycosaminoglycans (GAG), and associated plasma proteins [1]. Proteoglycans are core proteins anchored to the apical membrane of endothelial cells, to which several GAG chains are covalently attached [19]. There are many different types of proteoglycans, but syndecan-1 (a subtype of syndecan family from 1 to 4) is a primary target of prior endothelial glycocalyx investigations [20]. GAG chains that bind to proteoglycans include heparan sulfate (a major component of GAGs, comprising over $50 \%$ of GAGs in glycocalyx), chondroitin sulfates, dermatan sulfates, and possibly keratin sulfates [21]. These sulfated GAGs are negatively charged, enabling electrostatic interaction with plasma proteins [17]. In contrast, hyaluronan (hyaluronic acid) is a large linear molecule that does not bind to proteoglycans, but instead interacts with cell-membrane CD44. Hyaluronan also differs from other GAGs as it is not sulfated and is therefore uncharged. However, hyaluronan can form complexes with other sulfated GAGs, enabling it to sequester water and stabilize the gel-like structure of the glycocalyx [21]. Proteins such as albumin, fibrinogen, fibronectin, thrombomodulin, antithrombin III, superoxide dismutase, and cell-adhesion molecules all interact with GAGs.

\section{Glycocalyx function in health and disease}

In the healthy state, the glycocalyx serves as a barrier opposing vascular permeability, in part by serving as a negatively charged molecular sieve [3]. This "meshwork" limits transvascular movement of negatively charged and/or larger than $70-\mathrm{kDa}$ molecules. By establishing a transvascular albumin gradient, the intact glycocalyx regulates transvascular fluid flux (in accordance with the so-called "revised" Starling equation) [3, 4, 22]. Additionally, the glycocalyx senses fluid shear forces and transmits these forces to endothelial cells, initiating nitric oxide-mediated vasorelaxation. The glycocalyx provides anti-coagulant and anti-adhesive effects on the surface of endothelial cells. Moreover, it can shield endothelial cells from oxidative stress. In sepsis, the glycocalyx is degraded and cannot perform its normal functions, which leads to enhanced vascular permeability, tissue edema, augmented leukocyte adhesion, platelet aggregation, and dysregulated vasodilation (Fig. 1) [20]. Thus, it is hypothesized that these dysfunctions of glycocalyx, mainly resulting from its degradation, have a role in the early diagnosis and prognosis of sepsis; and restoration of the glycocalyx is a potential therapeutic target.

\section{Degradation of the endothelial glycocalyx during sepsis}

In sepsis, the degraded glycocalyx layer becomes thinner and more sparse, allowing plasma proteins (e.g., albumin) and fluid to move across the vascular wall, leading to tissue edema formation (Fig. 1) [6, 23]. This degradation 
releases glycocalyx components (such as syndecan-1, heparan sulfate, hyaluronan, chondroitin sulfates) into the plasma. Several enzymes mediate this degradation. Heparanase directly cleaves the heparan sulfate chains attached to core proteoglycans. Metalloproteinases (MMPs) are known to cleave proteoglycans (e.g. syndecan-1) directly from the endothelial cell membrane $[18,24]$. These specific enzymes are activated in inflammatory states by reactive oxygen species (ROS) and pro-inflammatory cytokines such as tumor necrosis factor alpha (TNF- $\alpha$ ) and interleukin-1beta (IL-1ß) [18, 20, 24-26]. Elevated heparanase expression can secondarily increase MMP expression in myeloma cells [27], suggesting cross-talk between sheddases.

Many preclinical and clinical studies have demonstrated a decrease in the thickness of the glycocalyx in sepsis. For example, Wiesinger et al. [28] found that mice treated with intravenous lipopolysaccharide (LPS) had a significant reduction in aorta glycocalyx thickness compared to controls $(0.27 \pm 0.012 \mu \mathrm{m}$ vs $0.14 \pm 0.017 \mu \mathrm{m}, p<0.0001)$. Furthermore, human umbilical venous endothelial cells showed a $50 \%$ reduction in the glycocalyx thickness when the cells were treated with TNF- $\alpha$ or LPS in vitro. Nieuwdorp et al. [29] used a human volunteer endotoxin model to study the glycocalyx in sepsis. In 13 healthy human subjects who received low-dose intravenous endotoxin, a significant decrease in sublingual glycocalyx thickness was observed $(0.60 \pm 0.1 \mu \mathrm{m}$ to $0.30 \pm 0.1 \mu \mathrm{m}, p<0.01)$ with a concurrent elevation of plasma hyaluronan $(62 \pm 18$ to 85 $\pm 24 \mathrm{ng} / \mathrm{mL}, p<0.05)$.

\section{Vascular heterogeneity of the glycocalyx layer}

Endothelial cells from different vascular beds (organ-specific) and vascular locations (arteriole, capillary, and venule) display different glycocalyxes [30]. In vivo, pulmonary artery endothelial cells are enriched with $\alpha$-galactose carbohydrates, while pulmonary microvascular endothelial cells are enriched with $\alpha$ - and $\beta$-N-acetylgalactosamine carbohydrates [31]. Schmidt et al. [18] found that the thickness of pulmonary microvascular endothelial glycocalyx of healthy mice $(n=43,1.67 \pm 0.09 \mu \mathrm{m})$ is substantially greater than that of cremasteric microvessels $(n=9,0.67$ $\pm 0.08 \mu \mathrm{m}$ ). Furthermore, mechanisms of glycocalyx shedding may differ across vascular beds, as septic induction of pulmonary endothelial heparanase was not observed in cremasteric endothelial cells [18]. The geographic heterogeneity of glycocalyx structure and degradation is a focus of current investigations.

\section{Measures of glycocalyx degradation in sepsis Direct bedside imaging of glycocalyx degradation during sepsis}

Orthogonal phase spectrometry (OPS) or sidestream dark field (SDF) imaging are intravital microscopy imaging techniques capable of assessing sublingual microvascular thickness at the bedside [16, 32]. The perfusion boundary region (PBR), a SDF-measured parameter that is inversely related to the glycocalyx thickness, has been proposed as a proxy of the glycocalyx thickness. Donati et al. [33] reported that the discriminative performance of PBR for the presence of sepsis as the area under the receiver operating characteristic curve (AUC) is 0.67 (95\% CI 0.52-0.82, $p=0.05$ ). While immediate assessment of glycocalyx degradation via handheld microscopy may be a promising diagnostic/prognostic test in early sepsis, concerns remain for inter-observer reliability and relevance of the sublingual microcirculation as a marker of clinically relevant organ injury. As such, further studies are required.

\section{Quantification of septic glycocalyx degradation using circulating biomarkers \\ Syndecan-1}

Studies demonstrate that syndecan-1 shedding is associated with both sepsis presence and severity (Table 1). Nelson et al. [34] reported that septic shock patients admitted to the intensive care unit (ICU; $n=18$ ) had a significantly higher median level of syndecan-1 compared to healthy controls $(\mathrm{n}=18 ; 246$ [interquartile range (IQR) $180-496] \mathrm{ng} / \mathrm{mL}$ vs 26 [IQR $23-31] \mathrm{ng} / \mathrm{mL}, p<0.001$ ). They also detected a correlation between syndecan-1 level with Sequential Organ Failure Assessment (SOFA) score $(r=0.48, p<0.05)$ and Cardiovascular SOFA score $(r=$ $0.69, p<0.01)$ during the first $24 \mathrm{~h}$ of admission. Despite these findings, there was no association between the median level of syndecan-1 and mortality. Steppan et al. [35] compared syndecan-1 levels among three groups; healthy volunteers $(n=18)$, patients after major abdominal surgery $(n=28)$, and severe sepsis/septic shock patients $(n=104)$. The mean syndecan-1 levels for both the surgery group $(50.5 \pm 46.9 \mathrm{ng} / \mathrm{mL})$ and sepsis group $(160 \pm 109 \mathrm{ng} / \mathrm{mL})$ were higher compared to controls $(20.5 \pm 5.05 \mathrm{ng} / \mathrm{mL})(p=$ 0.01 and $p<0.001$, respectively). Sallisalmi et al. [36] found that ventilated adult patients with septic shock $(n=20)$ in the ICU had significantly higher median syndecan- 1 than healthy controls. They also reported a significant correlation of syndecan-1 levels with SOFA score on day 1 of ICU admission $(r=0.654, p<0.002)$. Ostrowski et al. [37] showed a correlation between syndecan-1 levels and SOFA scores across a range of sepsis severities: local infection $(r=0.40, \quad p=0.004)$, sepsis $(r=0.34, p=$ $0.002)$, severe sepsis $(r=0.28, p=0.009)$, and septic shock $(r=0.60, p=0.051)$.

Puskarich et al. [38] compared median syndecan-1 levels at enrollment between patients who required intubation and those who did not and found that syndecan-1 levels in intubated patients were not significantly higher than in non-intubated patients $(181 \mathrm{ng} / \mathrm{mL}$ [IQR 61-568] vs $141 \mathrm{ng} / \mathrm{mL}$ [IQR 46-275], $p=0.06$ ). 


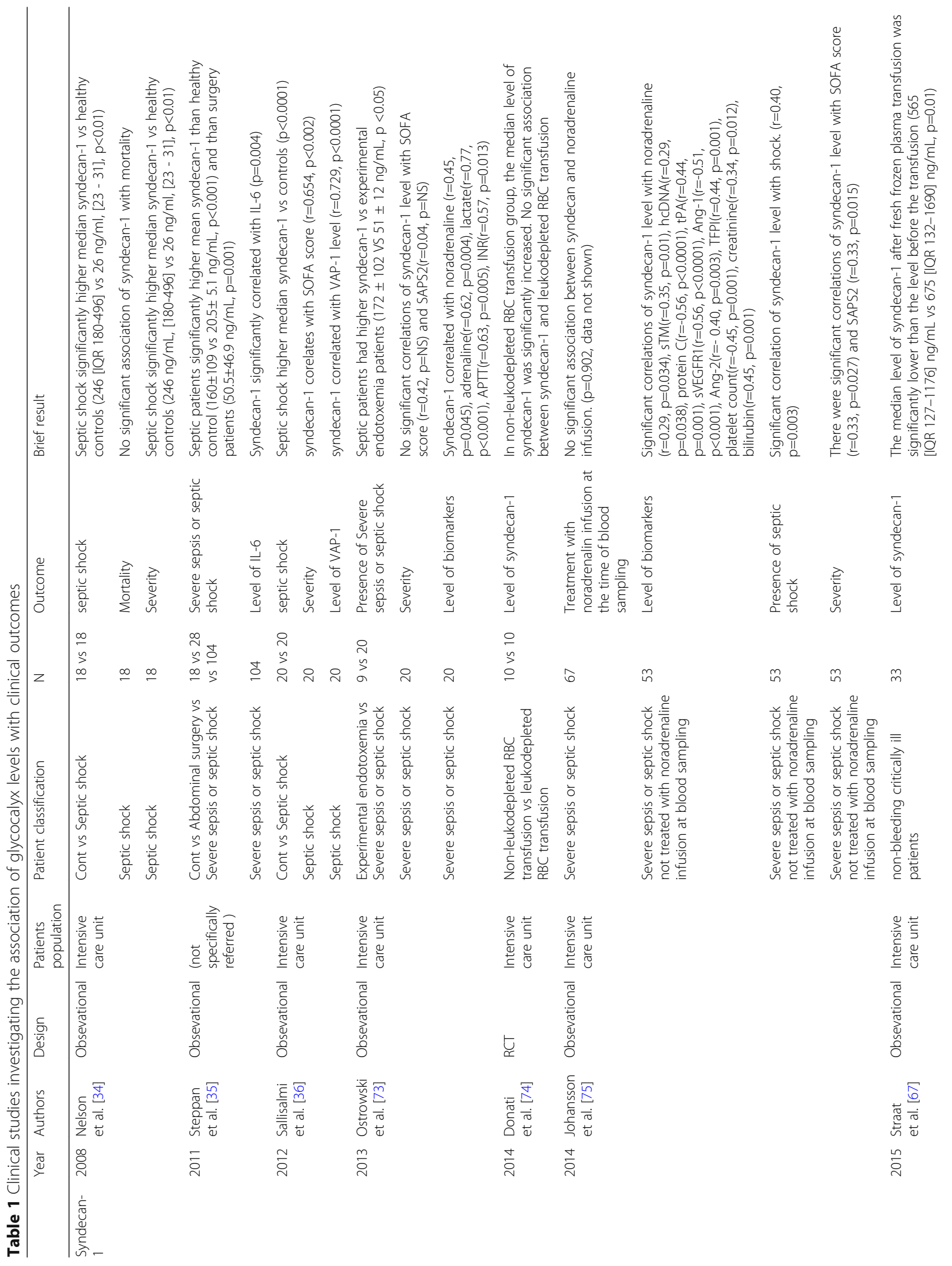




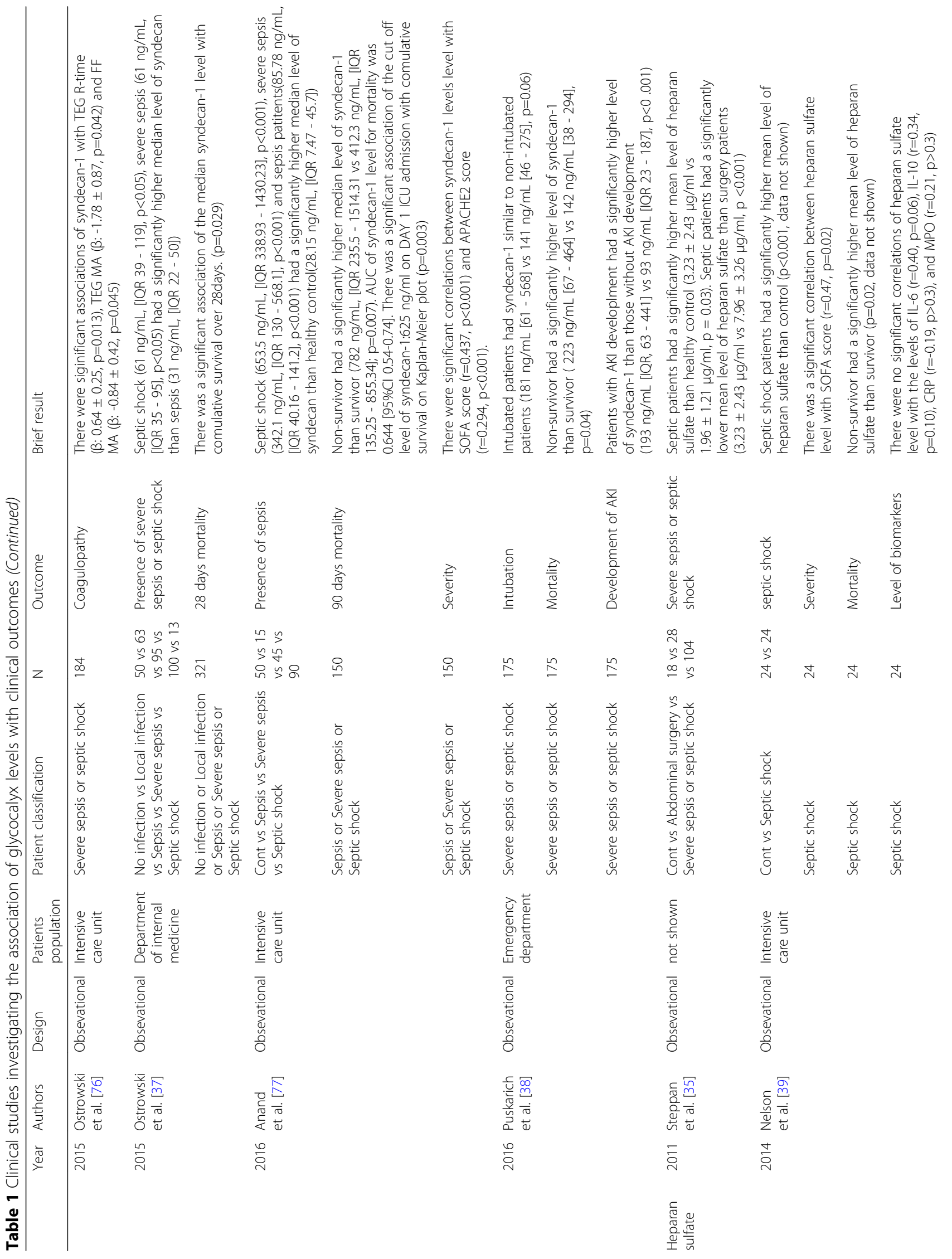




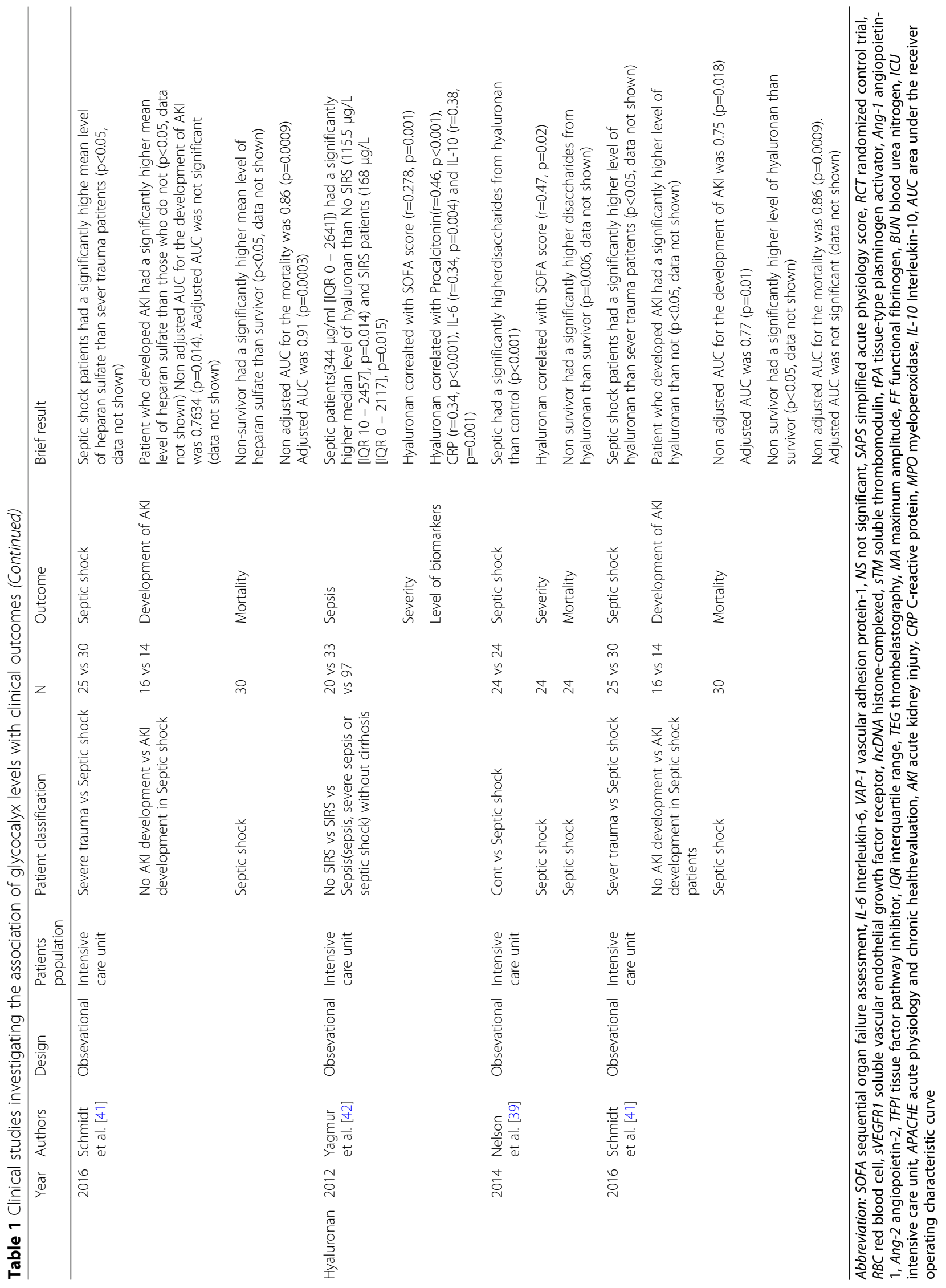


The receiver operating characteristic (ROC) curve analysis showed syndecan-1 levels alone poorly predicted intubation (AUC 0.58, 95\% CI 0.48-0.68). However, the syndecan-1 levels in patients who developed acute kidney injury (AKI) were higher than in those who did not $(193 \mathrm{ng} / \mathrm{mL}$ [IQR $63-441$ ] vs $93 \mathrm{ng} / \mathrm{mL}$ [IQR 23-187], $p<0.001)$.

\section{Heparan sulfate}

Heparan sulfate is also reported as elevated in sepsis. Steppan et al. [35] compared heparan sulfate levels among healthy volunteers $(n=18)$, patients after major abdominal surgery $(n=28)$, and severe sepsis/septic shock patients $(n=104)$. Mean heparan sulfate levels were significantly higher in the surgery group $(7.96 \pm 3.26 \mu \mathrm{g} / \mathrm{ml}, p<0.001)$ and sepsis group $(3.23 \pm 2.43 \mu \mathrm{g} / \mathrm{ml}, p=0.03)$ compared to control values $(1.96 \pm 1.21 \mu \mathrm{g} / \mathrm{ml})$. Additionally, septic patients had significantly lower mean levels of heparan sulfate than surgery patients $(3.23 \pm 2.43 \mu \mathrm{g} / \mathrm{ml}$ vs $7.96 \pm$ $3.26 \mu \mathrm{g} / \mathrm{ml}, p<0.001$ ). Nelson et al. [39] found fourfold significantly higher levels of heparan sulfate in 24 patients with septic shock compared to 24 controls scheduled for neurosurgery. Additionally, patients who died within 90 days had fivefold significantly higher levels of heparan sulfate compared to survivors. Schmidt et al. [40] investigated plasma levels of heparan sulfate in ICU patients mechanically ventilated with respiratory failure due to altered mental status $(n=4)$, indirect lung injury $(n=6)$, and direct lung injury $(n=7)$. They measured heparan sulfate levels in plasma collected upon ICU admission and found that patients with indirect lung injury had 23-fold higher median levels of heparan sulfate compared to normal donors. These patients also had increased heparan sulfate degradation activity in this (and a prior study [18]), indicating that mechanically ventilated patients with indirect lung injury might have elevated systematic heparanase activity. They also demonstrated that heparan sulfate plasma levels of the 17 ICU patients with mechanical ventilation were positively and significantly correlated with ICU length of stay $(r=0.58, p=0.01)$.

Similarly, Schmidt et al. [41] assessed urine heparin sulfate, which may primarily reflect renal glycocalyx degradation. They compared 30 medical ICU septic shock patients with 25 severe trauma patients in surgical ICU as controls and found significantly higher heparan sulfate levels in the urine of sepsis patients. They also found urine heparan sulfate levels to be highly prognostic for mortality with an AUC of 0.86 , which remained significant after adjusting for Acute Physiology and Chronic Health Evaluation (APACHE) II scores (AUC $0.91, p=0.0003)$. In this study, heparan sulfate was the only GAG that had a significant AUC with mortality after the adjustment; hyaluronic acid and chondroitin sulfate were not prognostic.

\section{Hyaluronan}

In the study by Schmidt et al. described above [41], the mean hyaluronan concentration in urine in septic shock patients was significantly higher than that from severe trauma patients. Sepsis non-survivors had a significantly higher mean level of hyaluronan at study entry compared to survivors. The ROC analysis showed a strong unadjusted AUC for hospital mortality of $0.86(p<0.001)$. Urinary hyaluronan also strongly predicted the later onset of renal failure (AUC 0.75, $p<0.02$ ). In a study of plasma hyaluronan, Yagmur et al. [42] classified 150 ICU patients without cirrhosis into three categories; no systemic inflammatory response syndrome (no-SIRS; $n=20$ ), SIRS $(n=33)$, and sepsis $(n=97)$. Sepsis patients had a higher median level of hyaluronan (344 ng/mg [IQR 0-2641]) versus no-SIRS (116 ng/mg [IQR 10-2457], $p=0.014$.) and SIRS (168 ng/mg [IQR 0-2117], $p=0.015$ ). However, they did not find a significant association between hyaluronan level and mortality.

\section{Mechanisms of glycocalyx degradation in sepsis Inflammation-induced glycocalyx degradation}

Many preclinical and clinical studies have demonstrated an association between inflammatory cytokines such as TNF- $\alpha$, IL- $1 \beta$, IL- 6 , and IL-10 and glycocalyx degradation biomarkers [28, 29, 39, 42-45]. Schmidt et al. [18] showed TNF- $\alpha$ was sufficient to induce glycocalyx degradation in septic mice. Furthermore, by using TNF- $\alpha$ receptor 1-deficient mice, they demonstrated that TNF- $\alpha$ signaling was necessary for glycocalyx degradation. This degradation was mediated by heparanase activation, as TNF- $\alpha$ treatment of lung microvascular endothelial cells increased both heparanase post-translational activation as well as heparan sulfate degradation activity.

Yang et al. [46] reported MMP15 (ADAM15) as a sheddase for CD44 ectodomain both in vivo and vitro. They found that in MMP15 knockdown endothelial cells, the shedding of CD44 induced by LPS treatment was greatly reduced. Similarly, in MMP15 knockout mice, the shedding of CD44 induced by cecal ligation puncture procedure is attenuated. However, the pathway of how MMP15 is activated during sepsis is still unclear in this study.

Recently angiopoietin 2 (Ang-2) has been investigated as a key mediator of glycocalyx degradation. Ang-2 is a protein secreted by endothelial cells in response to inflammatory stimuli. It serves as an intrinsic antagonist of angiopoietin 1 (Ang-1), preventing anti-inflammatory signaling usually induced by Ang-1 activation of its receptor TIE2. Lukasz et al. [47] found that Ang-2 treatment causes a rapid degradation of endothelial glycocalyx both in vivo and vitro, using a human umbilical vein endothelial cell line and mice. Han et al. [30] revealed that inhibiting Ang-2 leads to the reduced shedding of 
the endothelial glycocalyx and improved survival among mice with sepsis, concluding that the inhibiting Ang-2 and activating TIE2 might be a potential therapeutic target in sepsis.

While inflammatory stimuli can initiate glycocalyx degradation, glycocalyx integrity can also feed-back on the processes of inflammation themselves. Heparan sulfates and syndecan-1 bind to chemokines on the cell surface; release of these chemokines during degradation might amplify inflammation by promoting additional neutrophil recruitment [48-51]. This process has been elucidated in epithelial injury by Li et al. [52], who found that syndecan- 1 binds to $\mathrm{KC}$, a CXC chemokine, on the surface of lung epithelial cells. Matrilysin-mediated shedding of syndecan-1 ectodomain bound to $\mathrm{KC}$ created transepithelial chemokine gradients and controlled the neutrophil migration to the injured lung tissue. In endothelial cells, the exact balance between the effects of localizing chemokines on the cell surface and the effect of the release of the chemokine after the shedding remains to be further studied [48].

\section{Impact of fluid resuscitation on septic glycocalyx degradation}

Fluid resuscitation is an essential therapeutic treatment for sepsis and septic shock [53]. However, the type of fluid resuscitation used as well as the volume of resuscitation may significantly impact glycocalyx integrity.

\section{Data suggest that excessive fluid resuscitation might cause glycocalyx degradation}

Hypervolemia has been associated with increased glycocalyx degradation in sepsis. Several preclinical and clinical studies suggest that hypervolemia induces the release of atrial natriuretic peptide (ANP) by the cardiac atrium in response to mechanical wall stress, which in turn may degrade the glycocalyx [54]. Chappell et al. [55] conducted a pilot study using elective cardiac surgery patients with good cardiopulmonary function. They compared serum levels of ANP and biomarkers of glycocalyx degradation (syndecan-1, heparan sulfate, and hyaluronan) before and after volume loading with 6\% hydroxyethyl starch $130 / 0.4(20 \mathrm{ml} / \mathrm{kg} ; n=9)$ and acute normovolemic hemodilution $(n=9)$, in which the amount of blood drawn was simultaneously replaced with similar amounts of 6\% hydroxyethyl starch (HES) 130/0.4. The mean ANP level was significantly increased in volume loading group $(13.6 \pm 6.2 \mathrm{ng} / \mathrm{g}$ to $25.1 \pm 11.4$ ng/g albumin, $p<0.05$; data normalized to grams per deciliter of plasma albumin) whereas the normovolemic group had no significant increase in the mean ANP level $(13.4 \pm 3.5 \mathrm{ng} / \mathrm{g}$ to $14.8 \pm 5.6 \mathrm{ng} / \mathrm{g})$. The volume loading had a corresponding significant increase in mean levels of syndecan-1 $(24.8 \pm 8.1$ to $45.4 \pm 14.9 \mu \mathrm{g} / \mathrm{g}$ albumin $)$ and hyaluronan ( $32.6 \pm 5.5$ to $56.4 \pm 12.2 \mu \mathrm{g} / \mathrm{g}$ albumin) ( $p<0.05$ for each) while the normovolemic group produced no significant increased mean levels of all three biomarkers.

These findings were corroborated in a preclinical study that demonstrated that ANP independently induced glycocalyx degradation [56]. Isolated guinea pig hearts were first infused with Krebs-Henseleit buffer for an equilibration period. Then $6 \%$ HES solution was infused into the coronary vascular system for $20 \mathrm{~min}$ without ANP (control group, $n=6$ ) and with ANP (ANP group, $n=6$ ). The ANP group had a 9- to18-fold higher level of syndecan-1 in their coronary effluent at $6,10,15$, and 20 mins after the start of the HES infusion, compared to the control group. This corresponded to a decrease in glycocalyx thickness in coronary vessels of the isolated guinea pig hearts as observed by electron microscopy. Puskarich et al. [38] investigated the association between syndecan-1 levels of patients with severe sepsis or septic shock and the volume of fluid administered to emergency department patients. They categorized their 175 patients analyzed based on syndecan-1 level into a high group (syndecan-1 level $\geq 240 \mathrm{ng} / \mathrm{mL}$ ) and low group (syndecan-1 level $<240 \mathrm{ng} / \mathrm{mL}$ ) and found no difference in total crystalloid volume of fluid administered between high and low syndecan-1 groups ( $4.0 \mathrm{~L}$ [IQR 3.3-5.3] vs $3.5 \mathrm{~L}$ [IQR 2.4-5.0], $p=0.36$ ). The association between hypervolemia states with glycocalyx degradation in patients with sepsis remains unclear.

While intriguing, a causal association between ANP and glycocalyx shedding remains unproven. For example, Hahn [57] suggested that volume loading only modestly increases plasma concentrations of ANP. In addition, to our knowledge there is no proven mechanism by which ANP causes glycocalyx shedding. Further studies are therefore required.

\section{Use of colloids to protect glycocalyx integrity}

Albumin, a colloid commonly used for volume resuscitation, has been proposed to be glycocalyx-protective as it carries erythrocyte-derived sphingosine-1-phosphate (S1P) to the endothelium, where it can mediate glycocalyx recovery by suppressing MMP activity $[58,59]$. Jacob et al. [60] showed albumin prevents glycocalyx degradation more effectively than HES and $0.9 \%$ normal saline in their animal heart model. In this study, they did not actually assess the glycocalyx, but evaluated the effect of albumin and HES on vascular filtration, which reflects glycocalyx degradation. They used isolated guinea pig hearts pretreated with heparinase and perfused the hearts with albumin $(n=5), 6 \%$ HES $(n=5)$, or $0.9 \%$ normal saline $(n=5)$. The vascular fluid filtration was assessed as epicardial transudate formation. They found the mean levels of transudate formation were dependent on perfusion pressure and significantly lower in the $5 \%$ 
albumin group $\left(2.16 \pm 0.42 \mu \mathrm{l} \cdot \mathrm{min}^{-1} \cdot \mathrm{cm} \mathrm{H}_{2} \mathrm{O}^{-1}\right)$ compared to the $0.9 \%$ normal saline group $(p<0.05$, data not shown). Following this study, Jacob et al. [61] reported the protective effect of albumin in an ischemic model of guinea pig hearts. The model treated with albumin had significantly lower mean levels of syndecan-1 $(8.8 \pm 0.8$ $\mathrm{g} / \mathrm{g}$ dry weight $(\mathrm{DW})$ vs $6.6 \pm 0.8 \mathrm{~g} / \mathrm{g} \mathrm{DW}, p=0.032)$ and heparan sulfate $(808 \pm 176 \mathrm{~g} / \mathrm{g}$ DW vs $328 \pm 61 \mathrm{~g} / \mathrm{g} \mathrm{DW}$, $p<0.001)$ in the coronary effluent, as compared to non-albumin treated model. We did not identify clinical studies that investigated the utility of albumin administration in preventing glycocalyx degradation in sepsis.

Several preclinical studies found that fresh frozen plasma (FFP) had a protective effect on glycocalyx degradation in non-sepsis models. Kozar et al. [62] demonstrated that FFP inhibited glycocalyx degradation in rats with hemorrhagic shock compared to controls and lactate ringer (LR). They also measured the levels of syndecan-1 mRNA extracted from lung tissue of hemorrhagic shock rats. The syndecan- 1 mean mRNA level was significantly reduced in hemorrhagic shock $(1.39 \pm 0.22)$ compared to control $(3.03 \pm 0.22, p<0.02)$. They also found that the mean level of syndecan-1 mRNA was significantly higher in rats resuscitated with FFP $(2.76 \pm 0.03)$ than those resuscitated with LR $(0.82 \pm 0.03, p<0.001)$. Others have reported similar findings [63-65]. Conversely, Nelson et al. [66] found no difference in the mean plasma level of syndecan-1 and heparan sulfate in hemorrhagic shock model rats resuscitated with FFP $(n=10)$, albumin $(n=9)$, and Ringer's acetate (RA; $n=9$ ), after adjusting plasma volume difference caused by FFP, albumin, and RA.

Straat et al. investigated the effects of FFP on glycocalyx degradation in critical illness [67]. They compared the median levels of plasma syndecan-1 before and after FFP transfusion $(12 \mathrm{ml} / \mathrm{kg})$ in non-bleeding critically ill patients ( $n=33 ; 45 \%$ of their patients were septic). They found the median level of syndecan-1 after FFP transfusion was significantly lower than before FFP transfusion (565 [IQR 127-1176] pg/mL vs 675 [IQR 132-1690] pg/ $\mathrm{mL}, p=0.01$ ). These data are provocative but clearly further study is warranted.

\section{Potential therapeutic options for inhibiting glycocalyx degradation in sepsis}

Several novel molecules are being investigated as possible glycocalyx-protective therapeutics. As described above, S1P is a sphingolipid that may help improve glycocalyx integrity by inhibiting syndecan-1 shedding. S1P activates $\mathrm{S}_{1} \mathrm{P}_{1}$ receptor and the activation of $\mathrm{S}_{1} \mathrm{P}_{1}$ receptor attenuates the activity of MMPs causing syndecan-1 ectodomain shedding [59]. One prior study reported that serum S1P level is decreased in patients with sepsis and septic shock and associated with sepsis severity [68].
Heparin is postulated to protect the glycocalyx from degradation in sepsis by serving as an inhibitor of heparanase, which sheds heparan sulfate from the endothelial glycocalyx. A preclinical study reported that thinning of glycocalyx layer in lung microvessels is due to heparan sulfate degradation induced by TNF- $\alpha$-dependent heparanase activation; this was attenuated by heparin treatment in a LPS murine model [18]. Since the activation of heparanase can increase the level of MMP expression, heparin also may attenuate the increase of MMP expression levels by inhibiting heparanase activity [27]. Sulodexide (SDX), a highly purified extraction product from porcine intestinal mucosa, has been similarly reported to inhibit heparanase activity [69]. One preclinical study by Song et al. [70] reported that SDX treatment attenuated shedding of heparan sulfate and syndecan-4 in a septic mouse model.

Fibroblast growth factor (FGF) is a mediator of the physiological repair of glycocalyx. It is rapidly activated by circulating heparan sulfate fragments generated by degradation of glycocalyx and binds to FGF receptor, which conducts a signal for activating glycocalyx repairing molecules such as exostosin-1, an enzyme responsible for heparan sulfate synthesis. In sepsis, however, this repair process is significantly delayed because the signaling from activated FGF receptor is inhibited [71]. Enhancing this glycocalyx-repairing signal attenuated by sepsis is a potential therapeutic approach to reconstitute the glycocalyx layer and improve its function [72].

\section{Conclusions}

Glycocalyx degradation is gaining recognition as an important aspect of sepsis pathophysiology. Although the mechanisms of degradation are not fully elucidated, the increased plasma and urine levels of glycocalyx components may serve as diagnostic and prognostic biomarkers in sepsis. Some studies have investigated components that protect the glycocalyx from degradation, while others investigate the possibility of repair of a degraded glycocalyx. The relationship between the degradation and fluid therapy could yield other new insights into the prevention of the degradation. Finally, given the emerging role of the glycocalyx as a central part of sepsis pathophysiology, further studies are needed to establish therapeutic strategies to treat glycocalyx degradation in sepsis.

\footnotetext{
Abbreviations

AKl: Acute kidney injury; Ang-1: Angiopoietin 1; Ang-2: Angiopoietin 2; ANP: Atrial natriuretic peptide; APACHE: Acute Physiology and Chronic Health Evaluation; AUC: Area under the curve; DW: Dry weight; FFP: Fresh frozen plasma; FGF: Fibroblast growth factor; GAG: Glycosaminoglycans; HES: Hydroxyethyl starch; ICU: Intensive care unit; IL-10: Interleukin-10; IL13: Interleukin-1 beta; IL-6: Interleukin-6; IQR: Interquartile range; LPS: Lipopolysaccharide; LR: Lactate ringer; MMPs: Metalloproteinases; mRNA: Messenger ribonucleic acid; OPS: Orthogonal phase spectrometry; PBR: Perfusion boundary region; PG: Proteoglycans; RA: Ringer acetate; ROC: Receiver operating characteristic; ROS: Reactive oxygen species;
} 
S1P: Sphingosine-1-phosphate; SDF: Sidestream dark field; SDX: Sulodexide; SIRS: Systemic inflammatory response syndrome; SOFA: Sequential organ failure assessment; TNF-a: Tumor necrosis factor alpha

\section{Acknowledgments}

Not applicable.

\section{Funding}

Dr. Schmidt has received research grants from National Institute of Health, Institute of National Heart, Lung, and Blood Institute; R01 HL125371.

\section{Availability of data and materials}

Not applicable.

\section{Authors' contributions}

RU and NS conceived the article. ES provided basic science expertise. RU wrote the draft of the manuscript. All authors contributed to revising the manuscript and have given final approval of the version to be published.

\section{Ethics approval and consent to participate}

Not applicable.

\section{Consent for publication}

Not applicable.

\section{Competing interests}

The authors declare that they have no competing interests.

\section{Publisher's Note}

Springer Nature remains neutral with regard to jurisdictional claims in published maps and institutional affiliations.

\section{Author details}

'Department of Emergency Medicine, Beth Israel Deaconess Medical Center, 1 Deaconess Road, Boston, MA 02215, USA. ${ }^{2}$ Pulmonary Sciences and Critical Care Medicine, University of Colorado School of Medicine, 13001 E 17th PI, Aurora, CO 80045, USA.

\section{Received: 8 October 2018 Accepted: 12 December 2018}

Published online: 17 January 2019

\section{References}

1. Weinbaum S, Tarbell JM, Damiano ER. The structure and function of the endothelial glycocalyx layer. Annu Rev Biomed Eng. 2007;9:121-67.

2. Ince C, Mayeux PR, Nguyen T, Gomez H, Kellum JA, Ospina-Tascón GA Hernandez G, Murray P, De Backer D. The endothelium in sepsis. Shock. 2016:45:259-70

3. Alphonsus CS, Rodseth RN. The endothelial glycocalyx: a review of the vascular barrier. Anaesthesia. 2014;69:777-84

4. Woodcock TE, Woodcock TM. Revised Starling equation and the glycocalyx model of transvascular fluid exchange: an improved paradigm for prescribing intravenous fluid therapy. Br J Anaesth. 2012;108:384-94

5. Martin L, Koczera P, Zechendorf E, Schuerholz T. The endothelial glycocalyx: new diagnostic and therapeutic approaches in sepsis. Biomed Res Int. 2016; 2016:1-8.

6. Chelazzi C, Villa G, Mancinelli P, De Gaudio A, Adembri C. Glycocalyx and sepsis-induced alterations in vascular permeability. Crit Care. 2015;19:26.

7. Henrich M, Gruss M, Weigand MA. Sepsis-induced degradation of endothelial glycocalix. Sci World J. 2010;10:917-23.

8. Chappell D, Jacob M. Role of the glycocalyx in fluid management: Small things matter. Best Pract Res Clin Anaesthesiol. 2014;28:227-34.

9. Yang Y, Schmidt EP. The endothelial glycocalyx. Tissue Barriers. 2013;1: e23494.

10. Colbert JF, Schmidt EP. Endothelial and microcirculatory function and dysfunction in sepsis. Clin Chest Med. 2016;37:263-75.

11. Reitsma S, Slaaf DW, Vink H, van Zandvoort MAMJ, Egbrink MGA. The endothelial glycocalyx: composition, functions, and visualization. Pflugers Arch - Eur J Physiol. 2007;454:345-59.

12. Klitzman B, Duling BR. Microvascular hematocrit and red cell flow in resting and contracting striated muscle. Am J Phys. 1979;237:H481-90.
13. Vink H, Duling BR. Identification of distinct luminal domains for macromolecules, erythrocytes, and leukocytes within mammalian capillaries. Circ Res. 1996;79:581-9.

14. van Haaren PMA, VanBavel E, Vink H, Spaan JAE. Localization of the permeability barrier to solutes in isolated arteries by confocal microscopy. Am J Physiol Heart Circ Physiol. 2003;285:H2848-56.

15. Nieuwdorp M, van Haeften TW, Gouverneur MCLG, Mooij HL, van Lieshout MHP, Levi M, Meijers JCM, Holleman F, Hoekstra JBL, Vink H, Kastelein JJP, Stroes ESG. Loss of endothelial glycocalyx during acute hyperglycemia coincides with endothelial dysfunction and coagulation activation in vivo. Diabetes. 2006:55:480-6.

16. Nieuwdorp M, Meuwese MC, Mooij HL, Ince C, Broekhuizen LN, Kastelein JJP, Stroes ESG, Vink H. Measuring endothelial glycocalyx dimensions in humans: a potential novel tool to monitor vascular vulnerability. J Appl Physiol. 2008;104:845-52

17. Chappell D, Jacob M, Paul O, Rehm M, Welsch U, Stoeckelhuber M, Conzen $\mathrm{P}$, Becker BF. The glycocalyx of the human umbilical vein endothelial cell: an impressive structure ex vivo but not in culture. Circ Res. 2009;104:1313-7.

18. Schmidt EP, Yang Y, Janssen WJ, Gandjeva A, Perez MJ, Barthel L, Zemans RL, Bowman JC, Koyanagi DE, Yunt ZX, Smith LP, Cheng SS, Overdier KH, Thompson KR, Geraci MW, Douglas IS, Pearse DB, Tuder RM. The pulmonary endothelial glycocalyx regulates neutrophil adhesion and lung injury during experimental sepsis. Nat Med. 2012;18:1217-23.

19. Li L, Ly M, Linhardt RJ. Proteoglycan sequence. Mol BioSyst. 2012;8:1613.

20. Becker BF, Jacob M, Leipert S, Salmon AHJ, Chappell D. Degradation of the endothelial glycocalyx in clinical settings: searching for the sheddases. $\mathrm{Br} J$ Clin Pharmacol. 2015;80:389-402.

21. Broekhuizen LN, Mooij HL, Kastelein JJP, Stroes ESG, Vink H, Nieuwdorp M. Endothelial glycocalyx as potential diagnostic and therapeutic target in cardiovascular disease. Curr Opin Lipidol. 2009:20:57-62.

22. Curry FE, Adamson RH. Endothelial glycocalyx: permeability barrier and mechanosensor. Ann Biomed Eng. 2011:40:828-39.

23. Fleck A, Hawker F, Wallace PI, Raines G, Trotter J, Ledingham IM, Calman KC. Increased vascular permeability: a major cause of hypoalbuminaemia in disease and injury. Lancet. 1985;325:781-4.

24. Manon-Jensen T, Multhaupt HAB, Couchman JR. Mapping of matrix metalloproteinase cleavage sites on syndecan-1 and syndecan-4 ectodomains. FEBS J. 2013:280:2320-31.

25. Chappell D, Jacob M, Rehm M, Stoeckelhuber M, Welsch U, Conzen P, Becker BF. Heparinase selectively sheds heparan sulphate from the endothelial glycocalyx. Biol Chem. 2008;389:79-82.

26. Lipowsky HH, Lescanic A. The effect of doxycycline on shedding of the glycocalyx due to reactive oxygen species. Microvasc Res. 2013;90:80-5.

27. Purushothaman A, Chen L, Yang Y, Sanderson RD. Heparanase stimulation of protease expression implicates it as a master regulator of the aggressive tumor phenotype in myeloma. J Biol Chem. 2008;283:32628-36.

28. Wiesinger A, Peters W, Chappell D, Kentrup D, Reuter S, Pavenstädt $H_{4}$ Oberleithner $H$, Kümpers $P$. Nanomechanics of the endothelial glycocalyx in experimental sepsis. PLoS One. 2013:8:e80905.

29. Nieuwdorp M, Meuwese MC, Mooij HL, van Lieshout MHP, Hayden A, Lev M, Meijers JCM, Ince C, Kastelein JJP, Vink H, Stroes ESG. Tumor necrosis factor-a inhibition protects against endotoxin-induced endothelial glycocalyx perturbation. Atherosclerosis. 2009;202:296-303.

30. Han S, Lee S-J, Kim KE, Lee HS, Oh N, Park I, Ko E, Oh SJ, Lee Y-S, Kim D, Lee S, Lee DH, Lee K-H, Chae SY, Lee J-H, Kim S-J, Kim H-C, Kim S, Kim SH, Kim C, Nakaoka Y, He Y, Augustin HG, Hu J, Song PH, Kim Y-I, Kim P, Kim I, Koh GY. Amelioration of sepsis by TIE2 activation-induced vascular protection. Sci Transl Med. 2016;8:335ra55.

31. King J, Hamil T, Creighton J, Wu S, Bhat P, McDonald F, Stevens T. Structural and functional characteristics of lung macro- and microvascular endothelial cell phenotypes. Microvasc Res. 2004;67:139-51.

32. Massey MJ, Shapiro NI. A guide to human in vivo microcirculatory flow image analysis. Crit Care. 2016;20:1209.

33. Donati A, Damiani E, Domizi R, Romano R, Adrario E, Pelaia P, Ince C, Singer M. Alteration of the sublingual microvascular glycocalyx in critically ill patients. Microvasc Res. 2013:90:86-9.

34. Nelson A, Berkestedt I, Schmidtchen A, Ljunggren L, Bodelsson M. Increased levels of glycosaminoglycans during septic shock. Shock. 2008;30:623-7.

35. Steppan J, Hofer S, Funke B, Brenner T, Henrich M, Martin E, Weitz J, Hofmann U, Weigand MA. Sepsis and major abdominal surgery lead to flaking of the endothelial glycocalix. J Surg Res. 2011;165:136-41. 
36. Sallisalmi M, Tenhunen J, Yang R, Oksala N, Pettilä V. Vascular adhesion protein-1 and syndecan-1 in septic shock. Acta Anaesthesiol Scand. 2011;56:316-22.

37. Ostrowski SR, Gaïni S, Pedersen C, Johansson PI. Sympathoadrenal activation and endothelial damage in patients with varying degrees of acute infectious disease: An observational study. J Crit Care. 2015;30:90-6.

38. Puskarich MA, Cornelius DC, Tharp J, Nandi U, Jones AE. Plasma syndecan-1 levels identify a cohort of patients with severe sepsis at high risk for intubation after large-volume intravenous fluid resuscitation. J Crit Care. 2016:36:125-9.

39. Nelson A, Berkestedt I, Bodelsson M. Circulating glycosaminoglycan species in septic shock. Acta Anaesthesiol Scand. 2013;58:36-43.

40. Schmidt EP, Li G, Li L, Fu L, Yang Y, Overdier KH, Douglas IS, Linhardt RJ. The circulating glycosaminoglycan signature of respiratory failure in critically ill adults. J Biol Chem. 2014;289:8194-202.

41. Schmidt EP, Overdier KH, Sun $X$, Lin L, Liu X, Yang Y, Ammons LA, Hiller TD, Suflita MA, Yu Y, Chen Y, Zhang F, Cothren Burlew C, Edelstein CL, Douglas IS, Linhardt RJ. Urinary glycosaminoglycans predict outcomes in septic shock and acute respiratory distress syndrome. Am J Respir Crit Care Med. 2016;194:439-49

42. Yagmur E, Koch A, Haumann M, Kramann R, Trautwein C, Tacke F. Hyaluronan serum concentrations are elevated in critically ill patients and associated with disease severity. Clin Biochem. 2012:45:82-7.

43. Kolsen-Petersen JA. The endothelial glycocalyx: the great luminal barrier. Acta Anaesthesiol Scand. 2015:59:137-9.

44. Chappell D, Hofmann-Kiefer K, Jacob M, Rehm M, Briegel J, Welsch U, Conzen P, Becker BF. TNF-a induced shedding of the endothelial glycocalyx is prevented by hydrocortisone and antithrombin. Basic Res Cardiol. 2008; 104:78-89.

45. Lassalle P, Molet S, Janin A, Van der Heyden J, Tavernier J, Fiers W, Devos R, Tonnel AB. ESM-1 is a novel human endothelial cell-specific molecule expressed in lung and regulated by cytokines. J Biol Chem. 1996;271:20458-64.

46. Yang X, Meegan JE, Jannaway M, Coleman DC, Yuan SY. A disintegrin and metalloproteinase 15-mediated glycocalyx shedding contributes to vascular leakage during inflammation. Cardiovasc Res. 2018;114:1752-63.

47. Lukasz A, Hillgruber C, Oberleithner H, Kusche-Vihrog K, Pavenstädt H, Rovas A, Hesse B, Goerge T, Kümpers P. Endothelial glycocalyx breakdown is mediated by angiopoietin-2. Cardiovasc Res. 2017;113:671-80.

48. Proudfoot A, Johnson Z, Bonvin P, Handel T. Glycosaminoglycan interactions with chemokines add complexity to a complex system. Pharmaceuticals. 2017;10:70-25.

49. Axelsson J, Xu D, Na Kang B, Nussbacher JK, Handel TM, Ley K, Sriramarao P, Esko JD. Inactivation of heparan sulfate 2-O-sulfotransferase accentuates neutrophil infiltration during acute inflammation in mice. Blood. 2012;120: 1742-51.

50. Parish CR. The role of heparan sulphate in inflammation. Nat Rev Immunol. 2006;6:633-43

51. Wang L, Fuster M, Sriramarao P, Esko JD. Endothelial heparan sulfate deficiency impairs L-selectin- and chemokine-mediated neutrophil trafficking during inflammatory responses. Nat Immunol. 2005;6:902-10.

52. Li Q, Park PW, Wilson CL, Parks WC. Matrilysin shedding of syndecan-1 regulates chemokine mobilization and transepithelial efflux of neutrophils in acute lung injury. Cell. 2002;111:635-46.

53. Rhodes A, Evans LE, Alhazzani W, Levy MM, Antonelli M, Ferrer R, Kumar A, Sevransky JE, Sprung CL, Nunnally ME, Rochwerg B, Rubenfeld GD, Angus DC, Annane D, Beale RJ, Bellinghan GJ, Bernard GR, Chiche J-D, Coopersmith C, De Backer DP, French CJ, Fujishima S, Gerlach H, Hidalgo JL, Hollenberg SM, Jones AE, Karnad DR, Kleinpell RM, Koh Y, Lisboa TC, et al. Surviving Sepsis Campaign: International guidelines for management of sepsis and septic shock: 2016. Int Care Med. 2017;43:304-77.

54. Bruegger D, Schwartz L, Chappell D, Jacob M, Rehm M, Vogeser M, Christ F, Reichart B, Becker BF. Release of atrial natriuretic peptide precedes shedding of the endothelial glycocalyx equally in patients undergoing on- and offpump coronary artery bypass surgery. Basic Res Cardiol. 2011;106:1111-21.

55. Chappell D, Bruegger D, Potzel J, Jacob M, Brettner F, Vogeser $M$, Conzen $P$, Becker BF, Rehm M. Hypervolemia increases release of atrial natriuretic peptide and shedding of the endothelial glycocalyx. Crit Care. 2014;18:1.

56. Bruegger D. Atrial natriuretic peptide induces shedding of endothelial glycocalyx in coronary vascular bed of guinea pig hearts. Am J Physiol Heart Circ Physiol. 2005;289:H1993-9.
57. Hahn RG. Must hypervolaemia be avoided? A critique of the evidence. Anaesthesiol Intens Ther. 2014:47:1-8.

58. Adamson RH, Clark JF, Radeva M, Kheirolomoom A, Ferrara KW, Curry FE. Albumin modulates S1P delivery from red blood cells in perfused microvessels: mechanism of the protein effect. Am J Physiol Heart Circ Physiol. 2014;306:H1011-7.

59. Zeng Y, Adamson RH, Curry FRE, Tarbell JM. Sphingosine-1-phosphate protects endothelial glycocalyx by inhibiting syndecan-1 shedding. Am J Physiol Heart Circ Physiol. 2014;306:H363-72.

60. Jacob M, Bruegger D, Rehm M, Welsch U, Conzen P, Becker BF. Contrasting effects of colloid and crystalloid resuscitation fluids on cardiac vascular permeability. Anesthesiology. 2006;104:1223-31.

61. Jacob M, Paul O, Mehringer L, Chappell D, Rehm M, Welsch U, Kaczmarek I, Conzen P, Becker BF. Albumin augmentation improves condition of guinea pig hearts after $4 \mathrm{hr}$ of cold ischemia. Transplantation. 2009;87:956-65.

62. Kozar RA, Peng Z, Zhang R, Holcomb JB, Pati S, Park P, Ko TC, Paredes A. Plasma restoration of endothelial glycocalyx in a rodent model of hemorrhagic shock. Anesth Analg. 2011;112:1289-95.

63. Torres LN, Sondeen JL, Ji L, Dubick MA, Filho IT. Evaluation of resuscitation fluids on endothelial glycocalyx, venular blood flow, and coagulation function after hemorrhagic shock in rats. J Trauma Acute Care Surg. 2013;75:759-66

64. Peng Z, Pati S, Potter D, Brown R, Holcomb JB, Grill R, Wataha K, Park PW, Xue H, Kozar RA. Fresh frozen plasma lessens pulmonary endothelial inflammation and hyperpermeability after hemorrhagic shock and is associated with loss of syndecan 1. Shock. 2013;40:195202.

65. Haywood-Watson RJ, Holcomb JB, Gonzalez EA, Peng Z, Pati S, Park PW Wang W, Zaske AM, Menge T, Kozar RA. Modulation of syndecan-1 shedding after hemorrhagic shock and resuscitation. PLoS One. 2011;6:e23530.

66. Nelson A, Statkevicius S, Schött U, Johansson PI, Bentzer P. Effects of fresh frozen plasma, Ringer's acetate and albumin on plasma volume and on circulating glycocalyx components following haemorrhagic shock in rats. Intens Care Med Exp. 2016:4:1-14.

67. Straat M, Müller MC, Meijers JC, Arbous MS, Spoelstra de Man AM, Beurskens CJ, Vroom MB, Juffermans NP. Effect of transfusion of fresh frozen plasma on parameters of endothelial condition and inflammatory status in non-bleeding critically ill patients: a prospective substudy of a randomized trial. Crit Care. 2015;19:62-7.

68. Coldewey SM, Benetti E, Collino M, Pfeilschifter J, Sponholz C, Bauer M, Huwiler A, Thiemermann C. Elevation of serum sphingosine-1-phosphate attenuates impaired cardiac function in experimental sepsis. Sci Rep. 2016;6: 27594.

69. Masola V, Onisto M, Zaza G, Lupo A, Gambaro G. A new mechanism of action of sulodexide in diabetic nephropathy: inhibits heparanase-1 and prevents FGF-2-induced renal epithelial-mesenchymal transition. J Transl Med. 2012;10:213.

70. Song JW, Zullo JA, Liveris D, Dragovich M, Zhang XF, Goligorsky MS Therapeutic restoration of endothelial glycocalyx in sepsis. J Pharmacol Exp Ther. 2017;361:115-21.

71. Yang Y, Haeger SM, Suflita MA, Zhang F, Dailey KL, Colbert JF, Ford JA Picon MA, Stearman RS, Lin L, Liu X, Han X, Linhardt RJ, Schmidt EP. Fibroblast growth factor signaling mediates pulmonary endothelial glycocalyx reconstitution. Am J Respir Cell Mol Biol. 2017;56:727-37.

72. Rizzo AN, Dudek SM. Endothelial glycocalyx repair: building a wall to protect the lung during sepsis. Am J Respir Cell Mol Biol. 2017; 56:687-8.

73. Ostrowski SR, Berg RMG, Windeløv NA, Meyer MAS, Plovsing RR, Møller K, Johansson PI. Coagulopathy, catecholamines, and biomarkers of endothelial damage in experimental human endotoxemia and in patients with severe sepsis: A prospective study. J Crit Care. 2013;28:586-96.

74. Donati A, Damiani E, Luchetti M, Domizi R, Scorcella C, Carsetti A, Gabbanelli V, Carletti P, Bencivenga R, Vink H, Adrario E, Piagnerelli M, Gabrielli A, Pelaia P, Ince C. Microcirculatory effects of the transfusion of leukodepleted or non-leukodepleted red blood cells in patients with sepsis: a pilot study. Crit Care. 2014;18:R33.

75. Johansson PI, Haase N, Perner A, Ostrowski SR. Association between sympathoadrenal activation, fibrinolysis, and endothelial damage in septic patients: A prospective study. J Crit Care. 2014;29:327-33. 
76. Ostrowski SR, Haase N, Müller RB, Møller MH, Pott FC, Perner A, Johansson PI. Association between biomarkers of endothelial injury and

hypocoagulability in patients with severe sepsis: a prospective study. Crit Care. 2015;19:536.

77. Anand D, Ray S, Srivastava LM, Bhargava S. Evolution of serum hyaluronan and syndecan levels in prognosis of sepsis patients. Clin Biochem. 2016;49: $768-76$

Ready to submit your research? Choose BMC and benefit from:

- fast, convenient online submission

- thorough peer review by experienced researchers in your field

- rapid publication on acceptance

- support for research data, including large and complex data types

- gold Open Access which fosters wider collaboration and increased citations

- maximum visibility for your research: over $100 \mathrm{M}$ website views per year

At $\mathrm{BMC}$, research is always in progress.

Learn more biomedcentral.com/submissions 